\title{
ARTICLE \\ Ganoderma lucidum extract ameliorates MPTP-induced parkinsonism and protects dopaminergic neurons from oxidative stress via regulating mitochondrial function, autophagy, and apoptosis
}

\author{
Zhi-li Ren ${ }^{1}$, Chao-dong Wang ${ }^{1,2,3,4}$, Tao Wang ${ }^{5}$, Hui Ding ${ }^{1}$, Ming Zhou ${ }^{1}$, Nan Yang ${ }^{6}$, Yan-yong Liu ${ }^{6}$ and Piu Chan ${ }^{1,2,3,4}$
}

\begin{abstract}
Neuroprotection targeting mitochondrial dysfunction has been proposed as an important therapeutic strategy for Parkinson's disease. Ganoderma lucidum (GL) has emerged as a novel agent that protects neurons from oxidative stress. However, the detailed mechanisms underlying GL-induced neuroprotection have not been documented. In this study, we investigated the neuroprotective effects of GL extract (GLE) and the underlying mechanisms in the classic MPTP(1-methyl-4-phenyl-1,2,3,6tetrahydropyridine)-induced mouse model of PD. Mice were injected with MPTP to induce parkinsonism. Then the mice were administered GLE (400 $\mathrm{mg} \mathrm{kg}^{-1} \mathrm{~d}^{-1}$, ig) for 4 weeks. We observed that GLE administration significantly improved locomotor performance and increased tyrosine hydroxylase expression in the substantia nigra pars compact (SNpc) of MPTP-treated mice. In in vitro study, treatment of neuroblastoma neuro-2a cells with 1-methyl-4-phenylpyridinium (MPP $\left.{ }^{+}, 1 \mathrm{mmol} / \mathrm{L}\right)$ caused mitochondrial membrane potential collapse, radical oxygen species accumulation, and ATP depletion. Application of GLE $(800 \mu \mathrm{g} / \mathrm{mL})$ protected neuroblastoma neuro-2a cells against $\mathrm{MPP}^{+}$insult. Application of GLE also improved mitochondrial movement dysfunction in cultured primary mesencephalic neurons. In addition, GLE counteracted the decline in NIX (also called BNIP3L) expression and increase in the LC3-II/LC3-I ratio evoked by MPP ${ }^{+}$. Moreover, GLE reactivated MPP ${ }^{+}$-inhibited AMPK, $\mathrm{mTOR}$ and ULK1. Similarly, GLE was sufficient to counteract MPP ${ }^{+}$-induced inhibition of PINK1 and Parkin expression. GLE suppressed $\mathrm{MPP}^{+}$-induced cytochrome $C$ release and activation of caspase- 3 and caspase- 9 . In summary, our results provide evidence that GLE ameliorates parkinsonism pathology via regulating mitochondrial function, autophagy, and apoptosis, which may involve the activation of both the AMPK/mTOR and PINK1/Parkin signaling pathway.
\end{abstract}

keywords: ganoderma lucidum extract; parkinsonism; mitochondrial dysfunction; autophagy; apoptosis; MPTP

Acta Pharmacologica Sinica (2019) 40:441-450; https://doi.org/10.1038/s41401-018-0077-8

\section{INTRODUCTION}

Parkinson's disease (PD) is the second most common neurodegenerative disease. Abnormal accumulation of a-synuclein and formation of Lewy bodies are the pathological hallmarks of PD and eventually result in degeneration of dopaminergic (DA) neurons in the substantia nigra pars compact (SNpc) [1, 2]. However, the exact triggers and machinery for the progressive loss of DA neurons remain largely unclear. Mitochondrial dysfunction and increased oxidative stress have been demonstrated as key components of PD pathogenesis [3, 4]. Postmortem brains from PD patients display specific defects of mitochondrial complex I of the respiratory chain in the SNpc [5]. Reactive oxygen species (ROS), mainly generated by mitochondria in response to oxidative stress, cause damage to mitochondria, and initiate degenerative processes, including the activation of the apoptosis and necrosis cascades [6]. Recently, autophagy deregulation has been recognized as another essential aberrance in both familial and sporadic PD patients $[7,8]$. Numerous mutations or variants in genes related to lysosomal functions, such as glucocerebrosidase (GBA), vacuolar protein sorting 35 (VPS35), and sphingomyelin phosphodiesterase 1 , have been identified in familial PD patients [9-12]. Moreover, both GBA and VPS35 mutants inhibit autophagy activity and promote a-synuclein aggregation and DA neuron degeneration $[13,14]$.

Despite decades of endeavors in to seek therapies that can slow disease progression, PD remains an incurable disorder. Currently available treatments can only manage the symptoms but are unable to influence its initiation and progression [15]. Neuroprotection in the early stage of disease has been proposed as a promising strategy for delaying disease onset and halting the

\footnotetext{
${ }^{1}$ Department of Neurobiology, Neurology and Geriatrics, Xuanwu Hospital of Capital Medical University, Beijing Institute of Geriatrics, Beijing 100053 , China; ${ }^{2}$ Clinical and Research Center for Parkinson's Disease, Capital Medical University, Beijing 100053, China; ${ }^{3}$ Key Laboratory for Neurodegenerative Disease of the Ministry of Education, Beijing Key Laboratory for Parkinson's Disease, Parkinson Disease Center of Beijing Institute for Brain Disorders, Beijing 100053, China; ${ }^{4}$ National Clinical Research Center for Geriatrics Disorders, Beijing 100053, China; ${ }^{5}$ National Center for ADR Monitoring, Beijing 100045, China and ${ }^{6}$ Department of Pharmacology, Institute of Basic Medical Sciences, Center of Neuroscience, Chinese Academy of Medical Sciences \& School of Basic Medicine, Peking Union Medical College, Beijing 100005, China Correspondence: Piu Chan (pbchan@hotmail.com)
}

Received: 1 March 2018 Accepted: 14 June 2018

Published online: 10 July 2018 
progression [16, 17]. Such strategies have mostly targeted mitochondrial dysfunctions $[18,19]$. Creatine and coenzyme Q10, for instance, have been investigated in several clinical trials of PD. Unfortunately, most of the trials failed, and none of the neuroprotective agents tested showed sufficient benefits at the clinical level $[20,21]$.

Ganoderma lucidum (GL, also known as Lingzhi), a well-known traditional Chinese medicinal herb containing many bioactive compounds (including polysaccharides, triterpenoids, adenosine, and sterols) with multiple beneficial effects, and has been widely used in the treatment of disorders in Asia [22]. Most previous studies on GL have been focused on its antioxidant, immuno-modulating, and antitumor activities [23, 24]. However, its effects on PD have not been thoroughly investigated. In a randomized, double-blinded and placebo clinical trial, we treated 300 idiopathic PD patients (H\&Y 1-4) with Ganoderma lucidum extract (GLE). The 2-year follow-up assessments showed a disease-modifying effect of GLE, including slowing the progression of motor symptoms of PD at a dose of $4 \mathrm{~g} /$ day (unpublished data). Using a cell model, we have also suggested that GL extracts significantly prevent the production of microglia-derived proinflammatory and cytotoxic factors and downregulate TNF- $\alpha$ and IL-1 $\beta$ expression [25]. However, the detailed mechanisms underlying its effect have not been investigated. According to the previously reported effects on other disorders, we hypothesized that GL may confer protection against mitochondrial dysfunction and autophagy. In the present study, we tested these protective effects and mechanisms using the classic MPTP-induced mouse model of PD.

\section{MATERIALS AND METHODS}

Study subjects

GLE (batch number: A1301107), provided by PuraPharm International (HK) Ltd., was authenticated and standardized in accordance with the Pharmacopoeia of China 2010. GLE was prepared with methanol by low temperature extraction of the dried fruiting bodies of $\mathrm{GL}$ and standardized to contain $10 \% \mathrm{w} / \mathrm{w}$ polysaccharides, $0.3-0.4 \% \mathrm{w} / \mathrm{w}$ Ganoderic acid A, and $0.3-0.4 \%$ Ergosterol. For detailed fingerprints, please see Supplementary Information. GLE was prepared freshly using the corresponding vehicle (suspended in $0.5 \%$ carboxymethylcellulose sodium (CMC-Na) in vivo or dissolved in cultured medium in vitro).

Adult (8 weeks old), male C57BL6/J mice were purchased from Beijing Vital River Laboratory Animal Technology. The animals were maintained under standard temperature and humidity conditions with a 12-h light/dark cycle and fed a standard pellet diet and water ad libitum. All animals were treated in strict accordance with the NIH Guide for Care and Use of Laboratory Animals, and the studies were approved by the Animal Care Committee of Capital Medical University.

After 1 week of acclimatization, 15 animals were treated with normal saline (control) or MPTP (Sigma, St. Louis, MO, USA, $20 \mathrm{mg} /$ $\mathrm{kg}$, four injections at 2 -h intervals in 1 day), respectively. Afterward, both normal saline and MPTP-injected animals received an equivalent volume of $0.5 \%$ CMC-Na solution. Another group of MPTP animals were treated with daily intragastric administration of $400 \mathrm{mg} / \mathrm{kg}$ (stably suspended in $0.5 \%$ CMC-Na solution) GLE for 4 successive weeks.

\section{Behavioral test}

After 4 weeks of experimental dosing, motor functional performance using a beam walking test and rotarod test was assessed at least three times.

Beam walking task. The beam walking task consisted of placing the animal on a suspended $(50 \mathrm{~cm}$ above the floor), narrow wooden beam ( $100 \mathrm{~cm}$ long, $1.0 \mathrm{~cm}$ wide, and $1.0 \mathrm{~cm}$ tall). During training and testing, the mouse was placed at the starting zone facing its home cage, and a stopwatch started immediately upon release of the animal. Performance was assessed by recording the animal's latency to traverse the beam.

Rotarod task. The rotarod apparatus (Ugo Basile North America Inc., Collegeville, PA, USA) comprised a horizontal $\operatorname{rod}, 3 \mathrm{~cm}$ in diameter, separated by opaque plastic dividers in order to accommodate up to five mice per trial. In the rotarod task, the parameters were set as follows: initial speed, five revolutions per minute (rpm); maximum speed, 30 and $40 \mathrm{rpm}$ over the course of $300 \mathrm{~s}$. The duration that the mice remained on the rotarod was automatically recorded.

Immunohistochemistry $(\mathrm{IHC})$ and quantification

After the behavioral tests were finished, mice were transcardially perfused first with $0.01 \mathrm{M}$ phosphate-buffered saline (PBS) followed by $4 \%$ paraformaldehyde (PFA, $\mathrm{pH} 7.4$ ). In brief, coronal sections $(35 \mu \mathrm{M})$ were collected, and heat-mediated antigen retrieval was performed before the IHC staining protocol was begun. Then, sections were permeabilized in $0.3 \%$ Triton-X-100 (PBST) for $10 \mathrm{~min}$, and endogenous peroxidases were quenched using hydrogen peroxide. Brain sections were blocked in $10 \%$ fetal bovine serum (FBS) for $1 \mathrm{~h}$ and then incubated overnight at $4{ }^{\circ} \mathrm{C}$ with the primary antibody anti-tyrosine hydroxylase $(\mathrm{TH}, 1: 1000$, Millipore, specific for DA neuronal cells). Finally, the slices were mounted and captured using a CCD camera (Olympus, Japan). Number of $\mathrm{TH}^{+}$cells in the SNpc and the integrated optical density (IOD) of $\mathrm{TH}$-immunoreactive fibers in the striatum were determined using Image-Pro Plus Version 7.0 software (Media Cybernetics, Inc., MD, USA).

\section{Cell culture}

Mouse neuroblastoma cell lines (neuro-2a) were obtained from the Cell Resources Center of the Institute of Basic Medical Sciences of Chinese Academy of Medical Sciences and grown in minimum essential medium (Invitrogen, CA, USA) with 10\% FBS (Invitrogen, (A, USA) and $2 \mathrm{mM}$ glutamine, $100 \mathrm{U}$ penicillin, and $100 \mathrm{U}$ streptomycin per $\mathrm{mL}$ at $37{ }^{\circ} \mathrm{C}$ in a humidified $5 \% \mathrm{CO}_{2}$ incubator. For routine cell expansion, neuro-2a cells were grown until $\sim 80 \%$ confluence was achieved, followed by a 1:3 split. To clarify the neuroprotective effects of GLE, the cells were incubated with culture medium containing $1 \mathrm{mM}$ 1-methyl-4-phenylpyridinium $\left(\mathrm{MPP}^{+}\right.$, the metabolic product of MPTP, Sigma, St. Louis, MO, USA) in further studies.

\section{Cell viability assay and titration of the GLE doses}

Cytotoxic activity and cell viability were assayed using Cell Counting Kit (CCK-8) as described in the manual provided by the kit manufacturer (Dojindo Molecular Technologies, Japan). For titration of the GLE doses, neuro-2a cells cultured in 96-well plates were incubated with GLE at different concentrations $(100,200,400$, or $800 \mu \mathrm{g} / \mathrm{mL})$ for $0,6,12,24$, or $48 \mathrm{~h}$ to test cytotoxicity. Moreover, cells were incubated with the same concentrations of GLE for $48 \mathrm{~h}$ to estimate cell viability in the presence or absence of $\mathrm{MPP}^{+}$. At the observation endpoint, the culture medium was removed, and the cells were washed with PBS and then incubated with CCK-8 reagent for an additional $2 \mathrm{~h}$. CCK-8 was diluted with culture medium to form a $10 \%$ CCK-8 solution. The absorbance was measured at $450 \mathrm{~nm}$. Cell viability was evaluated as the ratio of the absorbance of the sample to that of control or untreated cells corresponding to each time point. By comparing the cell viability of the $\mathrm{MPP}^{+}$treated and non-treated cells after GLE administration, the optimal dose of GLE (highest increase in $\mathrm{MPP}^{+}$-treated cells, while lowest in non-treated cells) was determined and applied in all experiments. 
Membrane permeability assays for cell death

Neuro-2a cells were seeded in 12-well plate and cultured to approximately $50 \%$ confluence. Treatment with $800 \mu \mathrm{g} / \mathrm{mL}$ GLE combined with $1 \mathrm{mM} \mathrm{MPP}^{+}$for 6,12 , and $24 \mathrm{~h}$ was applied in each test. At the incubation endpoint, cells were stained with $0.04 \%$ trypan blue (Hartman-Leddon Co., Philadelphia, PA, USA) for 5-10 min at room temperature (RT). Cells were viewed by inverted microscopy. Trypan blue staining is regarded as an indicator of membrane permeabilization, and permeabilized cells are stained blue. The percentage of dead cells was calculated by counting the number of blue cells. At least 200 cells were counted for each assay.

Mitochondrial function assays in neuro-2a cells Neuro-2a cells were plated in corresponding chambers and treated with $1 \mathrm{mM} \mathrm{MPP}{ }^{+}$in the presence or absence of $800 \mu \mathrm{g} / \mathrm{mL}$ GLE for 6,9 , and $12 \mathrm{~h}$. The following experiments were applied to test mitochondrial function.

Mitochondrial membrane potential (MMP) assay. Cells were grown on a glass cover slip and stained using the MMPsensitive fluorescent dye JC-1 (Biotium, CA, USA) as previously described. Briefly, cells were incubated in medium containing $1 \times$ JC- 1 for $15 \mathrm{~min}$ at $37^{\circ} \mathrm{C}$. Cells were washed with $1 \times$ assay buffer and then PBS. Labeled cells were immediately monitored with fluorescence microscopy using a dual-bandpass filter.

Reactive oxygen species. To further assess mitochondrial biology, intracellular ROS production was measured in vitro. At each time point, ROS levels were assessed by loading cells with $5 \mu \mathrm{M}$ 2,7dichlorofluorescein diacetate (DCFH-DA, Sigma, St. Louis, MO, USA) for $30 \mathrm{~min}$ and then washing them twice with pre-warmed PBS. Labeled cells were analyzed using inverted fluorescence microscopy.

ATP generation. Moreover, we detected intracellular ATP levels using a bioluminescence ATP assay kit (Beyotime, China). The process was performed according to the manufacturer's instructions. Cells were harvested at set time points and lysed with lysis buffer. Then, each cell suspension was serially diluted and added to a 96-well white OptiPlate plate for ATP detection. The standard ATP control was also included in some wells (ten-fold serial dilution of the stock solution; $10 \mu \mathrm{M})$. Control wells included cells incubated in culture medium. Luminescence values were measured on a Modulus ${ }^{\mathrm{TM}}$ Microplate Reader and normalized to the protein content of each sample.

Immunofluorescence staining and confocal imaging

Cultured cells were seeded onto chamber slides for $24 \mathrm{~h}$, exposed to $1 \mathrm{mM} \mathrm{MPP}^{+}$and protected with $800 \mu \mathrm{g} / \mathrm{mL}$ GLE or vehicle for $6 \mathrm{~h}$. Then, cells were stained with $0.5 \mu \mathrm{M}$ MitoTracker Red CMH2XRos (Molecular Probes, Invitrogen, CA, USA), according to the manufacturer's guidelines and fixed in 4\% PFA for $20 \mathrm{~min}$. In the experiments, cells were subsequently permeabilized with $0.3 \%$ Triton X-100 in PBS for 30 min and blocked with 10\% FBS in PBS for $1 \mathrm{~h}$ at RT. Primary antibody incubation was carried out overnight at $4{ }^{\circ} \mathrm{C}$. The following antibodies were used: anti-LC3B (1:1000, Cell Signaling Technology, MA, USA) and anti-cytochrome C (1:200, Abcam, Cambridge, UK). Samples were labeled with Alexa Fluor (488 and 594)-conjugated secondary antibodies (Jackson ImmunoResearch, PA, USA) at $37^{\circ} \mathrm{C}$ for $1 \mathrm{~h}$. If applicable, stained cells were mounted with DAPI (Beyotime, China) and imaged using Olympus confocal laser microscopy.

\section{Western blot analysis}

The cellular samples were lysed in RIPA lysis buffer containing a protease and phosphatase inhibitor cocktail (Applygen Technologies Inc., China) and centrifuged at $12,000 \times g$ for 10 min at $4^{\circ} \mathrm{C}$.
The protein concentration of the supernatant was determined with a bicinchoninic acid assay. Briefly, equal amounts of proteins were loaded and transferred onto polyvinylidene fluoride membranes (Millipore, MA, USA). The membranes were incubated in blocking solution ( $5 \%$ milk in TBST containing $20 \mathrm{mM}$ Tris- $\mathrm{HCl}$, $150 \mathrm{mM} \mathrm{NaCl}$, and $0.1 \%$ Tween-20) at RT for $1 \mathrm{~h}$. The membranes were then incubated overnight (at $4{ }^{\circ} \mathrm{C}$ ) with the following primary antibodies: monoclonal rabbit antibodies against AMPKa, mTOR, ULK1, LC3B, NIX, caspase-3, caspase-9, Parkin (1:1000, Cell Signaling Technology, MA, USA), PINK1 (1:200, Santa Cruz, CA, USA), and $\beta$-actin (1:1000, Santa Cruz, CA, USA) in TBST containing $5 \%$ milk. After the membranes were washed with TBST, they were incubated with the corresponding secondary antibodies for $1 \mathrm{~h}$ at RT. Then, the membranes were imaged with the Chemiluminescence Imaging System (Tanon 5200, China). The intensity of blots was analyzed and compared using the Gel-Pro Analyzer. $\beta$-actin was used as a loading control in all Western blot analyses.

Primary cell culture

We obtained primary mesencephalic neuronal cells from newborn C57BL/6J mice using a previously described protocol but with some modifications. Briefly, the mesencephalon was isolated and incubated with $0.05 \%$ trypsin for $15 \mathrm{~min}$. The cells were suspended in DMEM, $10 \%$ FBS, $2 \mathrm{mM}$ L-glutamine, $100 \mathrm{U} / \mathrm{mL}$ penicillin and streptomycin. Cells were plated at a density of $1 \times 10^{5} \mathrm{cell} / \mathrm{mL}$ on poly- $D$-lysine-coated 8-well Lab-Tek coverglass chambers. After a 6-h incubation, the plating medium (DMEM) was exchanged for Neurobasal medium supplemented with B27 supplement (Invitrogen, (A, USA) and $25 \mu \mathrm{M}$ glutamine. All cultures were kept at $37^{\circ} \mathrm{C}$ in a humidified $5 \% \mathrm{CO}_{2}$-containing atmosphere.

\section{Mitochondrial axonal transport}

After 10 to 12 days in vitro, transient transfection of Mito-EGFP plasmids (kindly provided by Dr. Liu YanYong, Peking Union Medical College) was carried out using Lipofectamine 2000 (Invitrogen, CA, USA), and cells were imaged $24 \mathrm{~h}$ later. In brief, $\mathrm{MPP}^{+}$was added at a final concentration of $100 \mu \mathrm{M}$ with or without GLE $(800 \mu \mathrm{g} / \mathrm{mL})$ for $6 \mathrm{~h}$. Fluorescent time-lapse recordings were performed on the Live Cell Station (Olympus, Japan). For imaging of mitochondrial transport, we typically recorded neurons at a sampling rate of one frame every $5 \mathrm{~s}$ for $5 \mathrm{~min}$, with 50 -ms $C C D$ exposure and $2 \times 2$ binning. The velocity of mitochondrial transport was assessed using Velocity Demo software.

\section{Statistical analysis}

Data were statistically analyzed using one-way analysis of variance followed by LSD or Dunnett's T3 post hoc test depending on the results of the homogeneity of variance test. Summarized data were expressed as the mean \pm SEM. Statistical significance was set at $P<0.05$. All statistical analysis was undertaken using SPSS v17.

\section{RESULTS}

GLE treatment improved behavioral performance and protected against the loss of DA neurons in MPTP mice

To evaluate the effects of GLE on the MPTP-induced mouse model of parkinsonism, we first tested the motor behaviors of GLE-treated or untreated MPTP mice in beam walking and rotarod tests. As shown in Fig. 1a, without administration of GLE, the MPTP mice took significantly more time to cross the beam than the untreated mice. Similarly, in the rotarod test, the latency to fall from the rod was shortened in the MPTP group when the rod speed increased from 30 to $40 \mathrm{rpm}$. In contrast, administration of GLE significantly shortened the time to cross the beam and extended the time the mouse remained on the rotarod (Fig. 1b), suggesting that GLE treatment improves motor performance in MPTP mice. IHC showed marked loss of DA neurons and nerve terminals in the mice 4 weeks after MPTP injection. This toxic effect was ameliorated by $400 \mathrm{mg} / \mathrm{kg}$ 
a

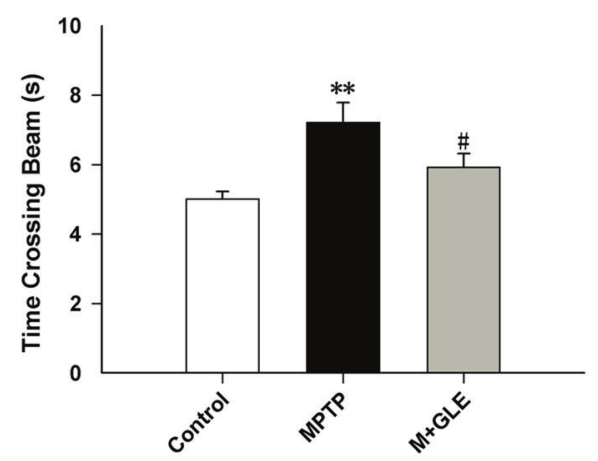

c

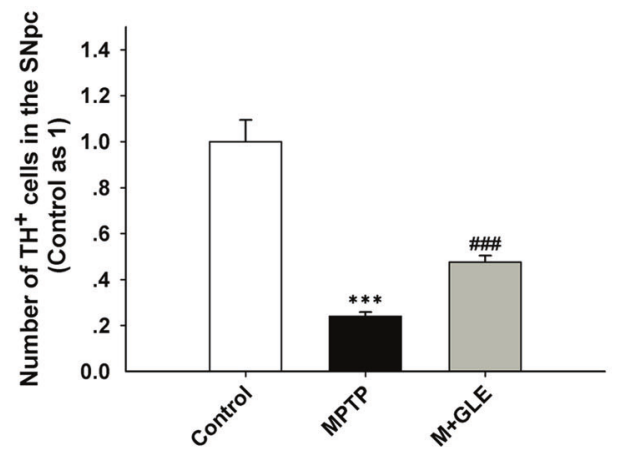

b

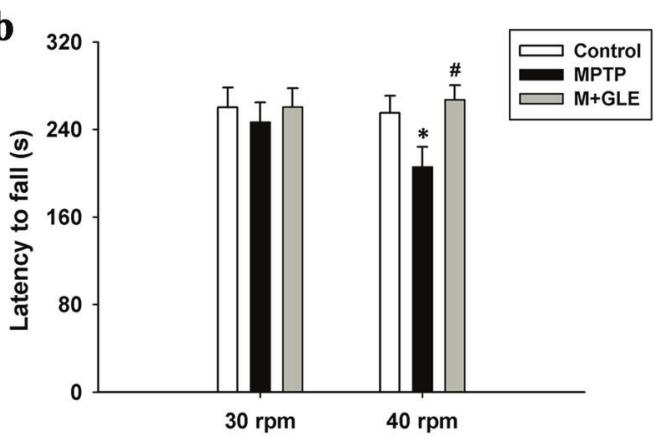

d

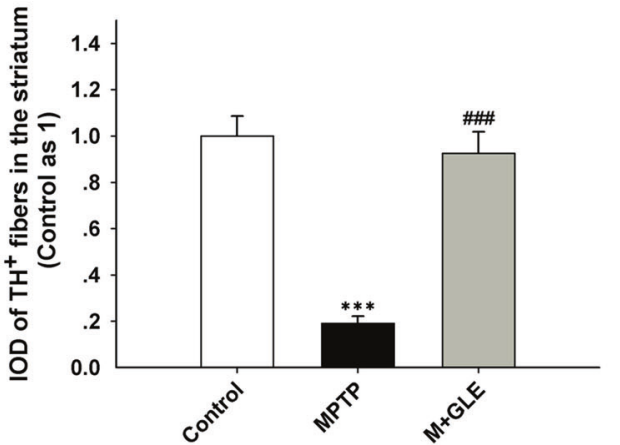

e

Control

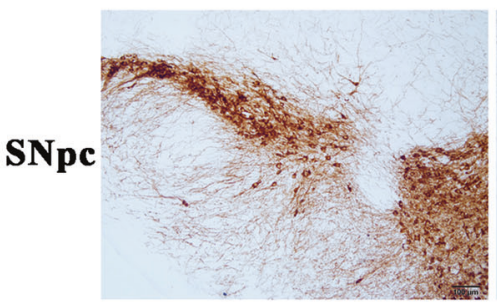

MPTP
M+GLE
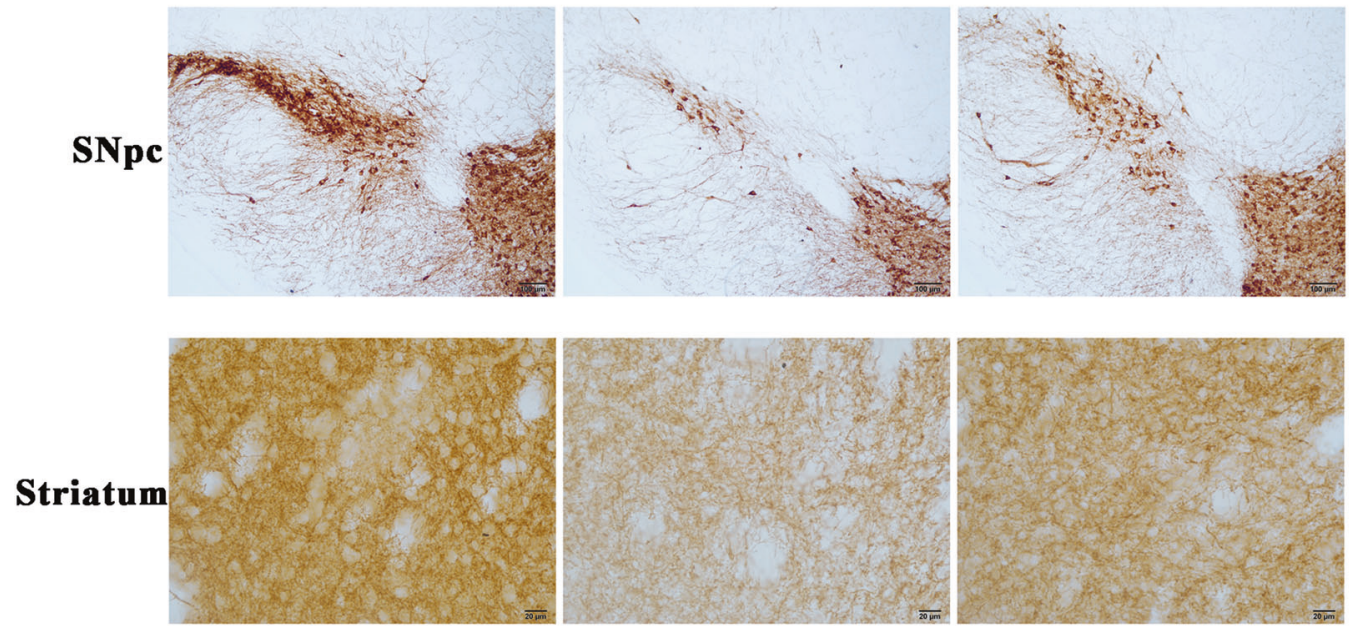

Fig. 1 GLE treatment promoted motor performance and protected against the loss of dopaminergic neuronal cells in MPTP-treated mice. a Time required to cross the beam in the beam walking test in each group. b Latency to fall in the rotarod test in each group. $\mathbf{c}$ Quantification of TH-positive cells in the substantia nigra pars compact (SNpc) (left). d IOD (integrated optical density) of TH-positive fibers in the striatum (right) among the different groups. e Representative immunohistochemical images of TH labeling in the SNpc (upper) and striatum (lower), respectively. Data are expressed as the mean $\pm \mathrm{SEM} ; n=15$ in each group, ${ }^{*} P<0.05,{ }^{* *} P<0.01,{ }^{* *} P<0.001$ vs. the control group; ${ }^{\#} P<0.05$, $\# \# P<0.001$ vs. the MPTP group

GLE, as the number of TH-positive cells in the SNpc was doubled in GLE-treated mice compared to that in the untreated mice, and the IOD of TH-positive projection fibers in the striatum was significantly increased to a level close to that in normal mice (Fig. 1c-e).

GLE treatment ameliorated the $\mathrm{MPP}^{+}$-evoked loss of cell viability and mitochondrial dysfunction

As shown in Fig. 2a, treatment with GLE alone did not cause any cytotoxic effect on cell viability up to the highest concentration $(800 \mu \mathrm{g} / \mathrm{mL})$. Next, we examined whether GLE can protect against $\mathrm{MPP}^{+}$-evoked neuronal damage. Cell viability was significantly inhibited by $1 \mathrm{mM} \mathrm{MPP}^{+}$in a time-dependent manner, reaching a nearly $90 \%$ reduction at $48 \mathrm{~h}$. This change was attenuated by GLE administration in a dose-dependent manner (Fig. 2b). Thus, $800 \mu \mathrm{g} / \mathrm{mL}$ was chosen as the optimal dose for all of the following experiments involving GLE treatment. GLE also decreased the amount of cell death induced by $\mathrm{MPP}^{+}$, with the highest reduction at $24 \mathrm{~h}$ of incubation (Fig. 2c).

$\mathrm{MPP}^{+}$causes mitochondrial dysfunction via inhibiting mitochondrial complex I and promoting the formation of oxygen free radicals (radical oxygen specimens, ROS). To test whether GLE can reduce $\mathrm{MPP}^{+}$-evoked mitochondrial dysfunction, we first labeled 


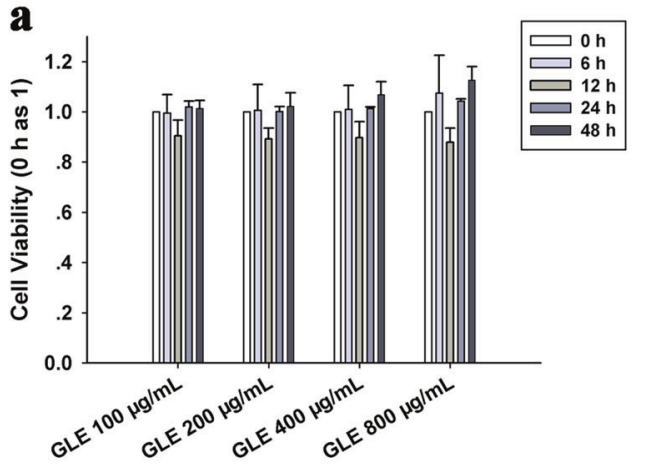

b

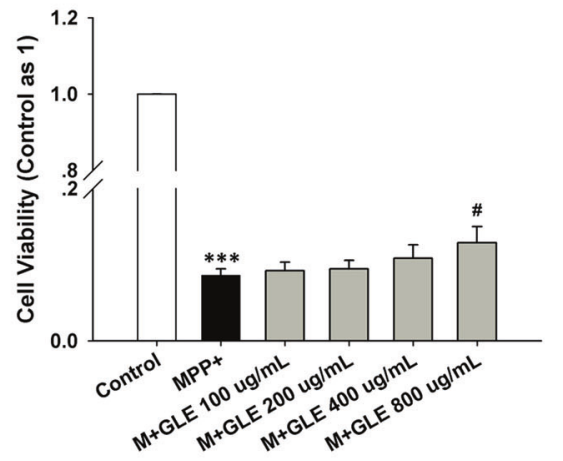

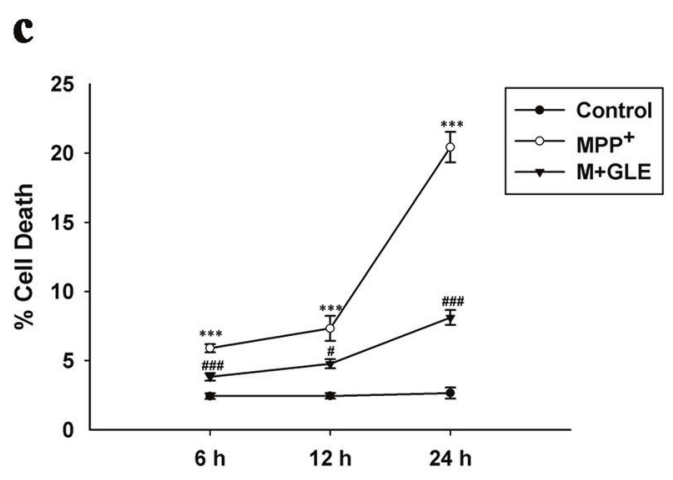

d Control
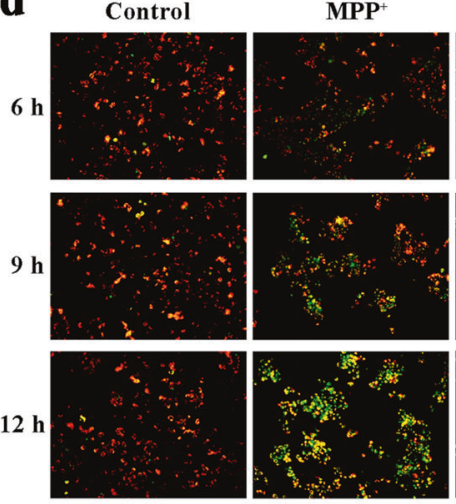

f

$\mathbf{e}$
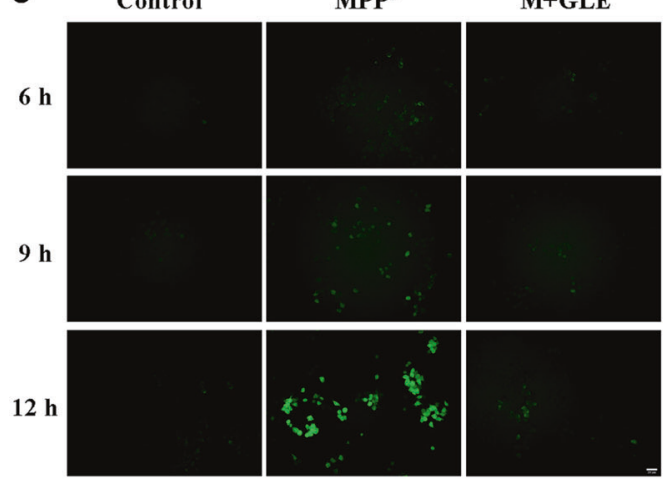

Fig. 2 GLE treatment prevented cellular and mitochondrial damage in neuro-2a cells following MPP ${ }^{+}$injury. Neuro-2a cells were exposed to $\mathrm{MPP}^{+}(1 \mathrm{mM}$, at the indicated time point) with or without GLE. a Cytotoxic effect of GLE at varying concentrations and incubation times on neuro-2a cells. $\mathbf{b}$ Effect of GLE on the $\mathrm{MPP}^{+}$-induced reductions in neuro-2a cell viability. Multiple concentrations of GLE were used to determine the concentration that was non-toxic to cells but caused the most significant increase in cell viability in the case of MPP ${ }^{+}$injury; $800 \mu \mathrm{g} / \mathrm{mL}$ was the dose of GLE selected for subsequent trials. c Percentage of dead cell was determined by the trypan blue membrane permeability assay as described in the Materials and Methods. $\mathbf{d}$ Representative image of mitochondria membrane potential (MMP) staining in each group. MMP was assessed by JC-1 dye. e Representative fluorescence microscopy image of neuro-2a cells stained with ROS-detecting probes (green). $f$ Concentrations of intracellular ATP using an ATP Determination Kit. Data are expressed as the mean \pm SEM (at least three independent experiments were performed); ${ }^{* *} P<0.001$ vs. the control group; ${ }^{\#} P<0.05,{ }^{\# \# \#} P<0.001$ vs. the MPP ${ }^{+}$group

the cells with the $\mathrm{JC}-1$ reagent and measured the red and green fluorescence. As shown in Fig. 2d, the ratios of red and green fluorescence in untreated cells changed only slightly throughout the experiment. In contrast, there was a continual decrease in red and increase in green fluorescence from 6 to $12 \mathrm{~h}$ in the $\mathrm{MPP}^{+}$-exposed cells. However, this alteration was significantly inhibited by GLE. We then monitored intracellular ROS production using specific probes. Compared to the very low fluorescence intensity observed in untreated cells, a significant increase in intracellular ROS was revealed after $12 \mathrm{~h}$ of $\mathrm{MPP}^{+}$incubation. However, the ROS accumulation was almost completely inhibited by GLE treatment, especially by prolonged incubation (Fig. 2e). In addition, co-incubation with GLE and $\mathrm{MPP}^{+}$for $12 \mathrm{~h}$ significantly increased the ATP concentration, which was sharply reduced by $\mathrm{MPP}^{+}$treatment alone (Fig. 2f).

To further evaluate the protective effects of GLE on mitochondria, we transfected the primary mesencephalic neuronal cells with Mito-EGFP and measured mitochondrial mobility by tracking the green fluorescence. As shown in Fig. 3a, mitochondria moved at a faster rate in the anterograde direction $(0.32 \mu \mathrm{m} / \mathrm{s})$, whereas they moved at an average speed of $0.28 \mu \mathrm{m} / \mathrm{s}$ in the retrograde direction. Compared to control cultures, $\mathrm{MPP}^{+}$cultured showed an obvious decrease in the mitochondrial speed in the anterograde direction and increased retrograde transport. 
a
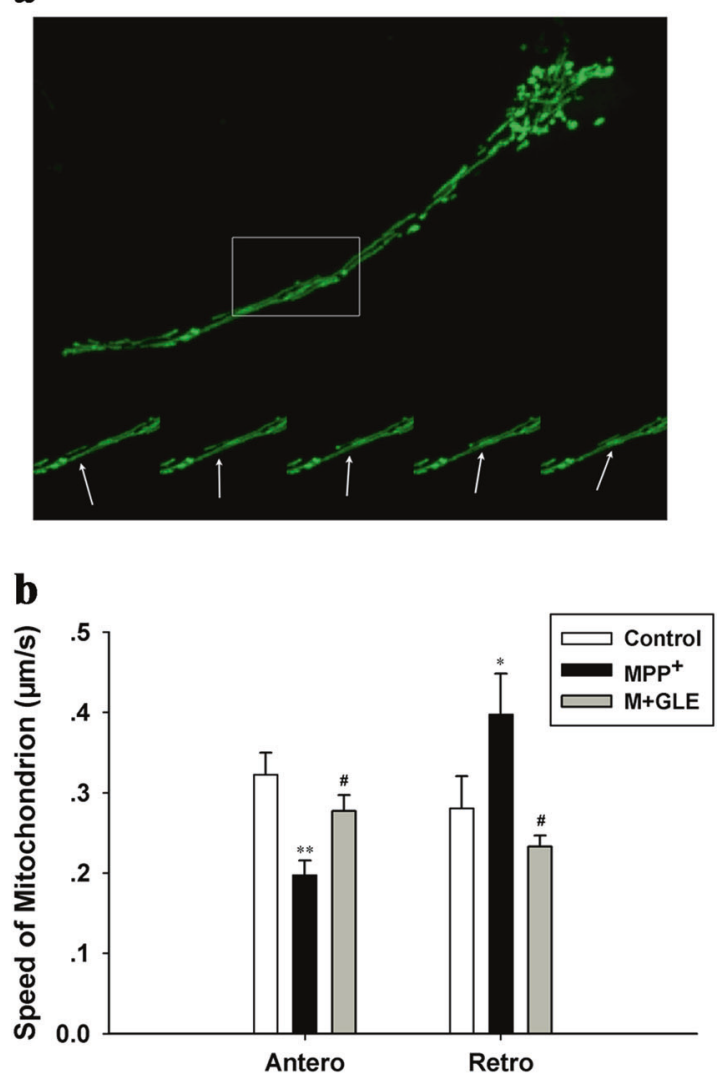

Fig. 3 GLE improved mitochondrial movement dysfunction in axons in $\mathrm{MPP}^{+}$-treated primary midbrain neuronal cells. a Representative view of mitochondrial movement along the axon; cultured neuronal cells were transfected with the Mito-EGFP plasmid and observed using the Live Cell Station. b The speed of moving mitochondria was calculated using Velocity Demo software. Bars represent the mean \pm SEM of three independent experiments conducted in duplicate. ${ }^{*} P<0.05$, ${ }^{*} P<0.01$ vs. the control group; ${ }^{\#} P<0.05$ vs. the $\mathrm{MPP}^{+}$group

However, following GLE treatment, these rates were obviously reversed (Fig. 3b).

GLE treatment ameliorated $\mathrm{MPP}^{+}$-evoked autophagy in neuro-2a cell lines

Autophagic influx is an important cellular event in DA neurons in response to pathological insults. To test whether GLE influences the $\mathrm{MPP}^{+}$-evoked autophagy, Western blot was utilized to measure the expression of NIX, a selective autophagy receptor for mitochondrial clearance, and LC3, the molecular marker for autophagy, as well as the conversion from LC3-I to LC3-II. The results revealed a decrease in NIX and increase in the LC3-II/LC3-I ratio over the course of incubation with $\mathrm{MPP}^{+}$. When GLE was added, NIX expression was dramatically elevated, and the LC3-II/ LC3-I ratio was significantly decreased accordingly (Fig. 4a). Consistently, immunocytochemical analysis displayed a diffuse pattern of LC3 fluorescence in control cells but a punctate pattern indicative of autophagy in cells treated with $\mathrm{MPP}^{+}$ (Fig. 4b). However, further treatment of these cells with GLE significantly reduced the percentage of cells with LC3 punctate foci. Moreover, the expression levels of autophagic proteins including AMP-activated protein kinase (AMPK), mammalian target of rapamycin (mTOR), and unc-51-like kinase 1 (ULK1) were decreased upon $\mathrm{MPP}^{+}$treatment, while subsequent addition of GLE reversed these alterations in neuro-2a cells (Fig. 4c). Similarly, treatment with $800 \mu \mathrm{g} / \mathrm{mL}$ GLE was sufficient to counteract the
$\mathrm{MPP}^{+}$-induced decline in the expression of PTEN-induced putative kinase 1 (PINK1) and E3 ubiquitin protein ligase (Parkin), two key proteins related to mitochondrial regulation in PD (Fig. 4d).

GLE treatment ameliorated $\mathrm{MPP}^{+}$-evoked apoptosis in neuro-2a cell lines

In addition to autophagy, $\mathrm{MPP}^{+}$exposure leads to increased apoptosis. We then examined whether this toxic effect can be protected by GLE in neuro-2a cells. As shown in Fig. 5a, confocal microscopy suggested that, upon $\mathrm{MPP}^{+}$challenge, the staining pattern of cytochrome $C$ changed from a condensed location in mitochondria to a diffuse distribution in the cytoplasm, while GLE treatment suppressed its release from mitochondria into the cytoplasm. Moreover, we found that $\mathrm{MPP}^{+}$induced a time-dependent decrease in Pro-caspase-3 (Pro-casp3) and Procaspase-9 (Pro-casp9) expression but an increase in activated caspase-3 (a-casp3) and activated caspase-9 (a-casp9) expression. Importantly, GLE treatment significantly suppressed these changes (Fig. 5b, c).

\section{DISCUSSION}

$\mathrm{GL}$ is a medicinal mushroom that has long been used in Asia as a folk remedy to promote health and longevity. Recent studies have indicated its roles in treating many diseases, such as cardiovascular diseases, diabetes, cancer, inflammation, and immune-related diseases [26, 27]. GL has also been evidenced to be neuroprotective in cerebral ischemic injury, epilepsy, Alzheimer's disease, PD, and Huntington's disease [28-33]. Studies have suggested that GL polysaccharides (GLPs) protect against $\mathrm{MPP}^{+}$and rotenone-induced apoptosis in primary DA cell cultures through inhibiting oxidative stress [34]. Moreover, our previous study confirmed the efficiency of $\mathrm{GL}$ in treating clinically diagnosed PD patients, while the current study further verifies the therapeutic effect of $G L$ on parkinsonism induced by MPTP. Administration of $400 \mathrm{mg} / \mathrm{kg}$ GLE alleviated the motor deficits and the selective loss of DA neurons caused by MPP ${ }^{+}$ toxicity. In vitro, GLE treatment attenuated $\mathrm{MPP}^{+}$-induced mitochondrial dysfunction, autophagy, and apoptosis in neuro-2a cell lines, as well as mitochondrial transport impairment in primary cultured mesencephalic neuronal cells.

The roles of GL in neuroprotection have been studied for several years $[35,36]$. Most of the previous studies have been focused on its antioxidant capacity against oxidative stress, which has also been highlighted in MPTP-induced parkinsonism in mice [28, 37]. In contrast to previous studies, our results revealed that GLE protected $\mathrm{MPP}^{+}$-damaged neuroblastoma cells by simultaneously repairing mitochondrial dysfunction, autophagy deregulation, and apoptosis, the three interactive molecular events essential for controlling neuronal survival in PD and other neurodegenerative disorders [38-40]. More importantly, we found that GLE attenuated the impairment of mitochondrial transport and movement by maintaining MMP and protected DA neuron synaptic function. Mitochondrial movement is critical for cellular function and survival, especially in neurons with a polarized structure [41-43]. Kim-Han et al. reported that mitochondrial transport defects can be blocked by antioxidant $\mathrm{N}$-acetyl-cysteine in a manner independent of ATP, calcium, free radical species, and even the caspase- 3 pathway. Intriguingly, GLE may, similar to N-acetyl-L-cysteine, correct the pathology of $\mathrm{MPP}^{+}$-induced pathology in DA neurons via a direct effect on mitochondria but not on ROS [44].

The molecular pathways by which $G L$ regulates mitochondria function and autophagy have not been elaborated in neurons. Mitochondrial dysfunction, which leads to ROS accumulation, ATP depletion, and subsequent energy failure, is a contributing factor to neurodegeneration in PD. With the dramatic decrease in intracellular ATP levels, the energy-sensing kinase AMPK is activated, which initiates autophagy [45]. On the other hand, ROS serve as signaling molecules in the activation of autophagy [46]. Our study showed 
$\mathbf{a}$

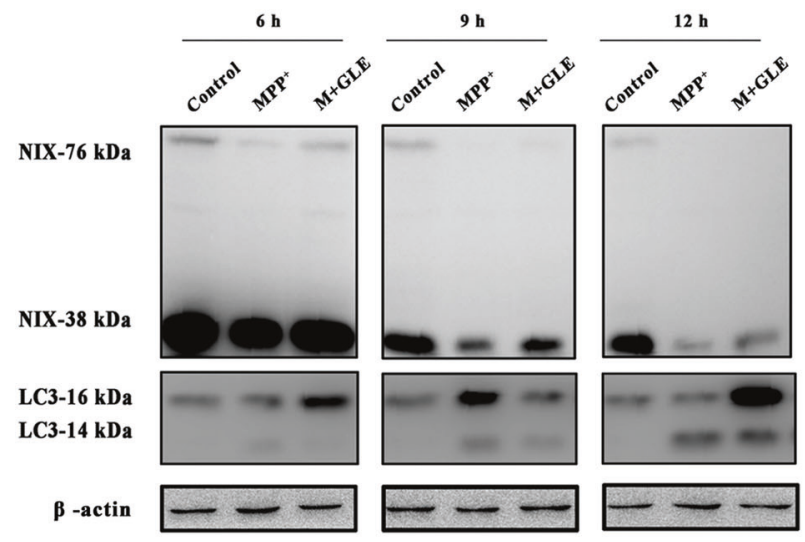

b

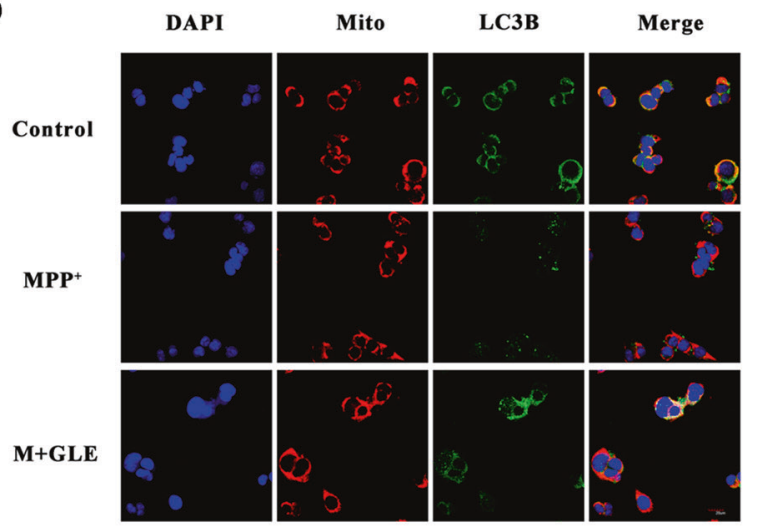

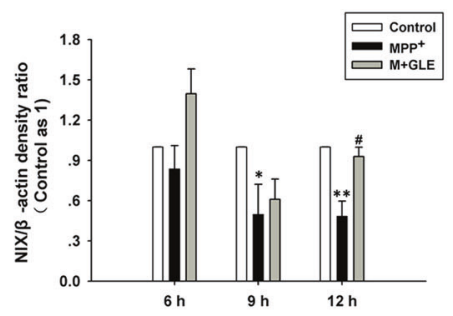
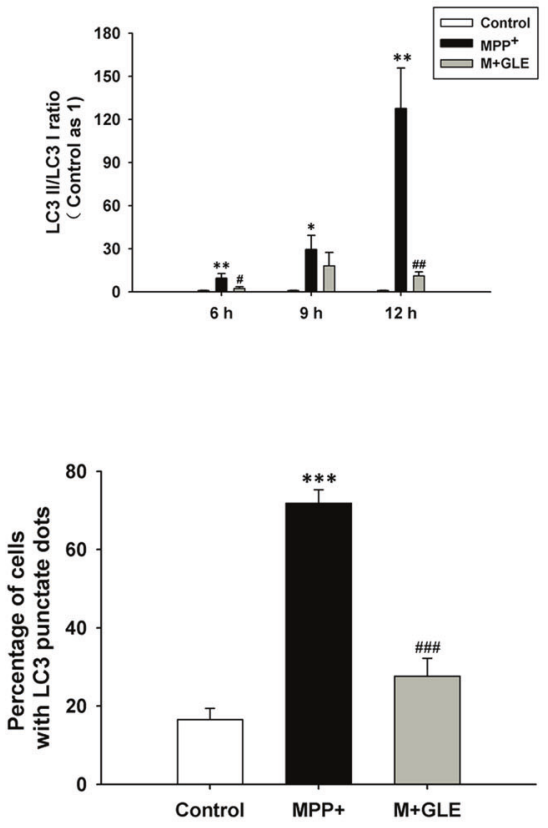

C

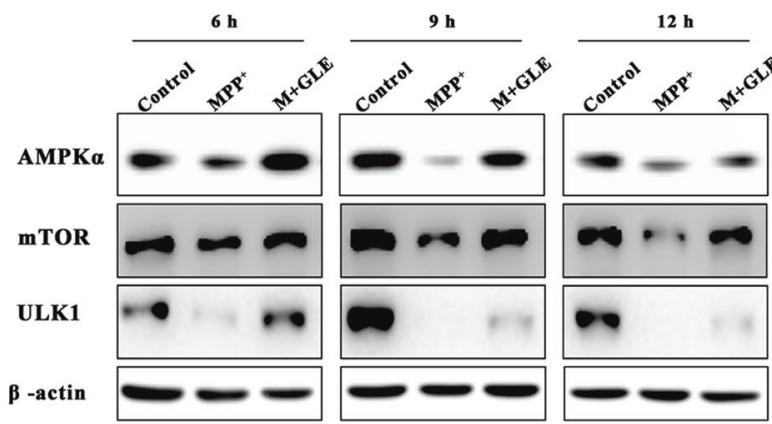

d

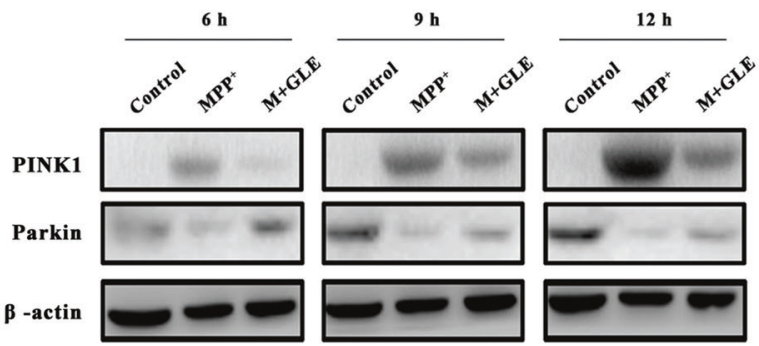

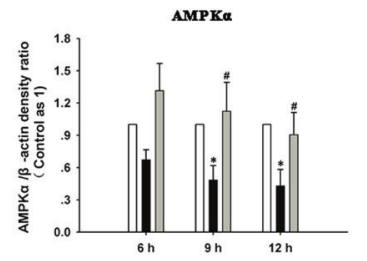
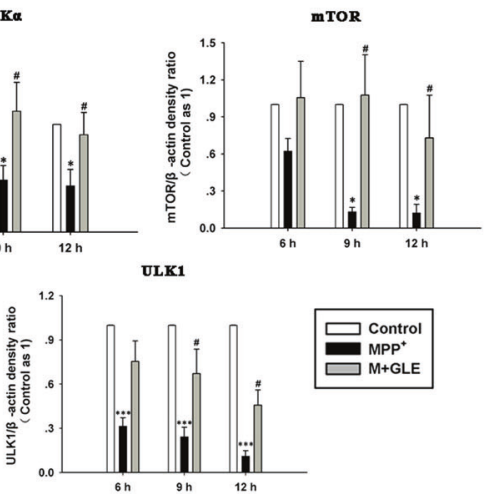

control $\mathrm{MPP}_{\mathrm{M}+\mathrm{GLE}}^{+}$
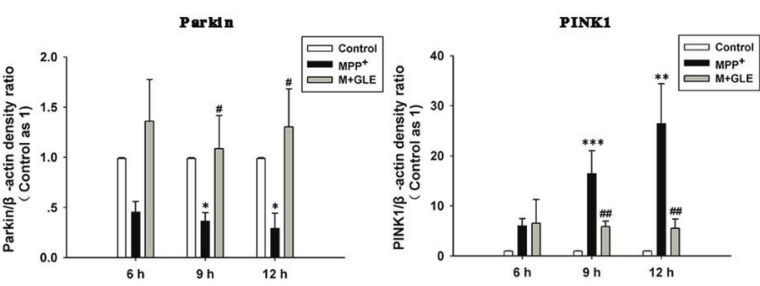

Fig. 4 GLE administration regulated autophagy induced by $\mathrm{MPP}^{+}$in neuro-2a cell lines. a Western blot was performed to test the effect of GLE on autophagic events at 6,9 , and $12 \mathrm{~h}$ after $\mathrm{MPP}^{+}$treatment (left), and the immunoreactive band was quantified (right). The occurrence of autophagy was analyzed by examining the LC3-I-to-LC3-II conversion, expressed as the LC3-II/LC3-I ratio. b Representative confocal images of LC3B (green) and mitochondria (MitoTracker dye, red). Nuclei were counterstained with 4',6'-diamidino-2-phenylindole (DAPI, blue). Cells were treated with $\mathrm{MPP}^{+}(1 \mathrm{mM})$ in the absence or presence of GLE $(800 \mu \mathrm{g} / \mathrm{mL})$ for $6 \mathrm{~h}$. Scale bar, $20 \mu \mathrm{m}$ (left). Quantification of the percentage of cells with LC3 punctate staining (right). c Representative images of Western blot with antibodies against AMPK $\alpha$, mTOR, and ULK1 (left). Quantification of these proteins from the Western blot analysis (right). d Western blot analysis of PINK1 and Parkin expression levels (left). Quantification analysis of PINK1 and Parkin expression from Western blot (right). The bands were quantified by densitometric analysis, and results shown represent the mean \pm SEM of combined results from three independent experiments. ${ }^{*} P<0.05,{ }^{* * *} P<0.001$ vs. the control group; ${ }^{\#} P<0.05$, ${ }^{\# \#} P<0.001$ vs. the MPP $^{+}$group 

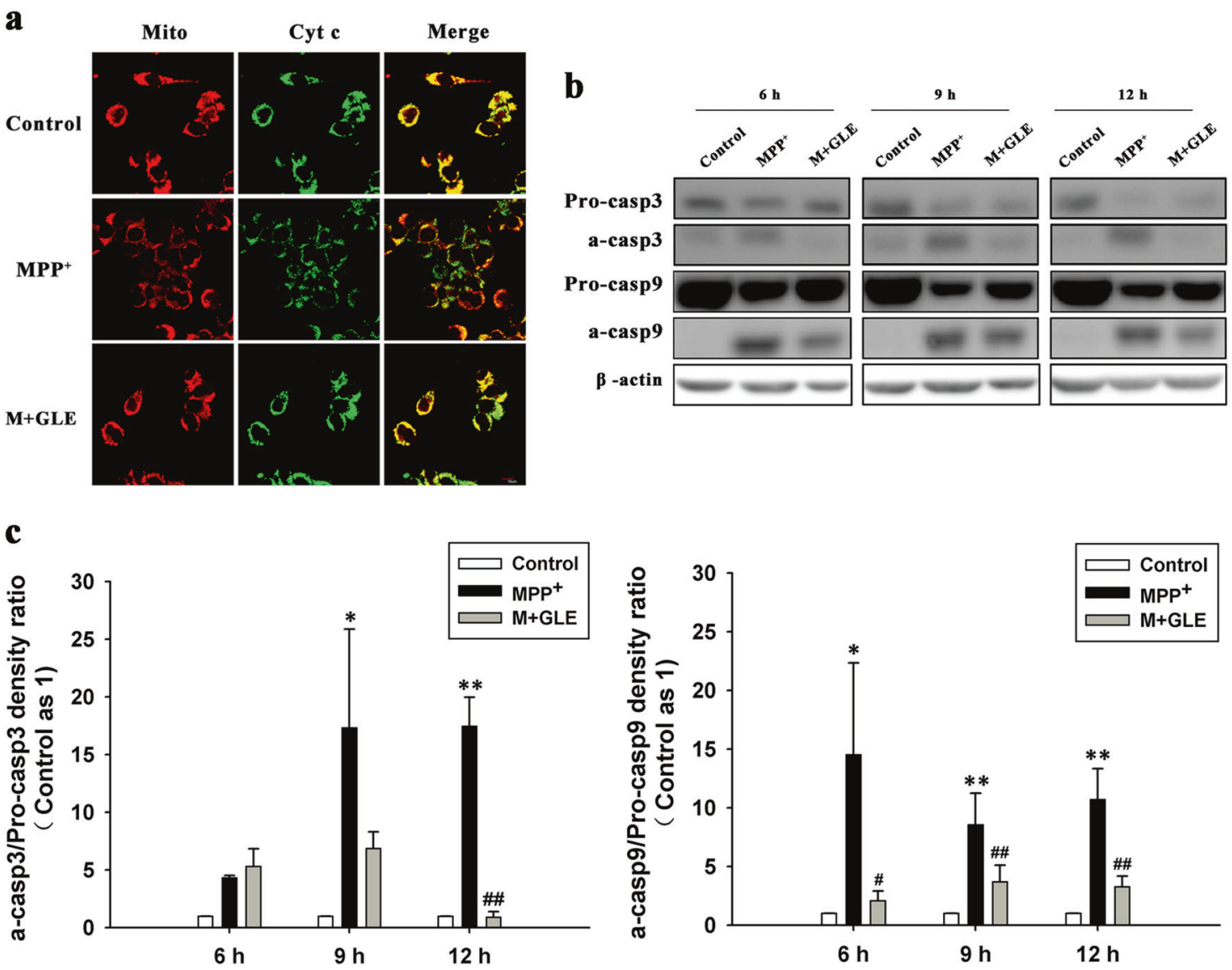

Fig. 5 GLE administration was resistant to $\mathrm{MPP}^{+}$-mediated apoptosis in neuro-2a cell lines. a Immunofluorescence analysis of the effect of GLE on cytochrome $c$ released from mitochondria in MPP+-treated neuro-2a cells. Cells were treated with $\mathrm{MPP}^{+}(1 \mathrm{mM})$ in the absence or presence of GLE $(800 \mu \mathrm{g} / \mathrm{mL})$ for $6 \mathrm{~h}$. Cells were co-stained with MitoTracker red and the anti-cytochrome c monoclonal antibody. Scale bar, $20 \mu \mathrm{m}$. b Immunoblot analysis of caspase-3 and caspase-9 using the caspase- 3 and caspase- 9 antibodies, which detected endogenous levels of full-length caspase (Pro-casp3, $35 \mathrm{kDa}$; Pro-casp9, $51 \mathrm{kDa}$ ) and the large fragment of caspase resulting from cleavage (a-casp3, $17 \mathrm{kDa}$; acasp9, $39 \mathrm{kDa})$. c The optical density analysis of caspase- 3 and caspase- 9 proteins. ${ }^{*} P<0.05,{ }^{* *} P<0.01 \mathrm{vs}$. the control group, and ${ }^{\#} P<0.05$, ${ }^{\# \#} P$ $<0.01$ vs. the $\mathrm{MPP}^{+}$group. Data are the mean values $\pm \mathrm{SEM}, n=3$

that GLE protects neuronal cells via promoting the activation of both the AMPK/mTOR/ULK1 and PINK1/Parkin pathways, the key molecular pathways that regulate autophagy and mitochondrial functions in PD. The AMPK/mTOR signaling pathway plays a crucial role in activating autophagy under energy-deprived conditions in cells. AMPK is a major metabolic energy sensor that negatively regulates $\mathrm{mTOR}$, leading to ULK1-AMPK interaction to stimulate autophagy $[47,48]$. On the other hand, PINK1 and Parkin act as a ubiquitous core signaling pathway coupling mitochondrial stress to mitochondrial surveillance to regulate mitochondrial dynamics, mitophagy, and biogenesis [49, 50]. Over the last decade, PINK1/ Parkin-dependent mitochondrial quality control has emerged as one of the key mechanisms underlying PD pathology [51]. More importantly, the PINK1/Parkin pathway has recently been identified as a new player in autophagy activation in mitochondria and mitophagy induction to protect DA neurons from oxidative stress and degeneration [52]. Our observation that GLE could, at least partially, reactivate both the AMPK/mTOR/ULK1 and PINK1/Parkin pathways that were compromised by $\mathrm{MPP}^{+}$in neuroblastoma cells suggests that GLE may be directly or indirectly involved in the regulatory network of mitophagy in the presence of oxidative challenges. However, further evidence from animal models are needed to confirm the roles of these pathways.

Which component(s) of GLE mediates its functions in mitochondrial and autophagy responses in DA neurons is also unclear. Pharmacological analyses have demonstrated that GLE is a highly complex compound $[23,53,54]$. The constituents of GLE include polysaccharides, triterpenoids, steroids, peptides, fungal lysozyme, ergosterol, and fenugreek extract $[22,55]$. Among these components, polysaccharides are normally thought to be major active substances with antioxidant, antitumor, and immunostimulant properties. GLPs protect against oxidative stress in renal, hepatic, myocardial, and neuronal cells $[56,57]$. In particular, GLPs were shown to protect DA neurons against $\mathrm{MPP}^{+}$and rotenoneinduced oxidative stress via elevating mitochondrial complex I activity and the MMP and reducing ROS formation [34]. Although GLP has not been linked to autophagy, polysaccharides from other herbs, such as Fuzi, Astragalus, and Rosa rugosa, protect against cytotoxicity by increasing autophagy through activation of the AMPK/mTOR pathway, as we observed in the DA neurons [58-60]. GLP might be one of the major components of GL that modulates the stress resistance, mitochondrial maintenance, and autophagy response to $\mathrm{MPP}^{+}$-induced parkinsonism in the mouse model. Further in vitro and in vivo studies are needed to confirm this hypothesis, refine the active components of $\mathrm{GL}$, and optimize its recipe for the treatment of PD.

In summary, we provided compelling in vitro and in vivo evidence that GLE improves parkinsonian symptoms and pathology via regulating both mitochondrial function and the autophagic response to oxidative stress. These modulations may involve the activation of both the AMPK/mTOR and PINK1/Parkin signaling pathway and directly or indirectly contribute to the mitophagy 
and mitochondrial biogenesis essential for the survival of neuronal cells. The current study demonstrated that GL may hold promise as a potential neuroprotective agent for PD.

\section{ACKNOWLEDGEMENTS}

This study was supported by grants from the China Postdoctoral Science Foundation (2015M581133) and Beijing Postdoctoral Research Foundation (2015ZZ-63); from Beijing Municipal Administration of Hospitals' Mission Plan, Code: SML20150803 and Beijing Municipal Science \& Technology Commission No. Z171100000117013 to Dr. Piu Chan; and from The National Key R\&D Program of China (2016YFC1306000) to Dr. Chao-dong Wang.

\section{ADDITIONAL INFORMATION}

The online version of this article (https://doi.org/10.1038/s41401-018-0077-8) contains supplementary material, which is available to authorized users.

Competing interests: The authors declare no competing interests.

Publisher's note: Springer Nature remains neutral with regard to jurisdictional claims in published maps and institutional affiliations.

\section{REFERENCES}

1. Hirsch EC, Jenner P, Przedborski S. Pathogenesis of Parkinson's disease. Mov Disord. 2013;28:24-30

2. Shulman JM, De Jager PL, Feany MB. Parkinson's disease: genetics and pathogenesis. Annu Rev Pathol. 2011;6:193-222.

3. Exner N, Lutz AK, Haass C, Winklhofer KF. Mitochondrial dysfunction in Parkinson's disease: molecular mechanisms and pathophysiological consequences. EMBO J. 2012;31:3038-62.

4. Subramaniam SR, Chesselet MF. Mitochondrial dysfunction and oxidative stress in Parkinson's disease. Prog Neurobiol. 2013;106-107:17-32.

5. Schapira AHV, Cooper JM, Dexter D, Clark JB, Jenner P, Marsden CD. Mitochondrial complex I deficiency in Parkinson's disease. J Neurochem. 1990;54:823-7.

6. Zuo L, Motherwell MS. The impact of reactive oxygen species and genetic mitochondrial mutations in Parkinson's disease. Gene. 2013;532:18-23.

7. Lynch-Day MA, Mao K, Wang K, Zhao M, Klionsky DJ. The role of autophagy in Parkinson's disease. Cold Spring Harb Perspect Med. 2012;2:a009357.

8. Zhang H, Duan C, Yang H. Defective autophagy in Parkinson's disease: lessons from genetics. Mol Neurobiol. 2015;51:89-104.

9. Dehay B, Martinez-Vicente M, Caldwell GA, Caldwell KA, Yue Z, Cookson MR, et al. Lysosomal impairment in Parkinson's disease. Mov Disord. 2013;28:725-32.

10. Foo JN, Liany H, Bei JX, Yu XQ, Liu J, Au WL, et al. Rare lysosomal enzyme gene SMPD1 variant (p.R591C) associates with Parkinson's disease. Neurobiol Aging 2013:34:2890 e13-5.

11. Sidransky $\mathrm{E}$, Lopez $\mathrm{G}$. The link between the GBA gene and parkinsonism. Lancet Neurol. 2012;11:986-98.

12. Vilarino-Guell C, Wider C, Ross OA, Dachsel JC, Kachergus JM, Lincoln SJ, et al VPS35 mutations in Parkinson disease. Am J Hum Genet. 2011;89:162-7.

13. Du TT, Wang L, Duan CL, Lu LL, Zhang JL, Gao G, et al. GBA deficiency promotes SNCA/alpha-synuclein accumulation through autophagic inhibition by inactivated PPP2A. Autophagy. 2015;11:1803-20.

14. Tang FL, Erion JR, Tian Y, Liu W, Yin DM, Ye J, et al. VPS35 in dopamine neurons is required for endosome-to-golgi retrieval of Lamp2a, a receptor of chaperonemediated autophagy that is critical for alpha-synuclein degradation and prevention of pathogenesis of Parkinson's disease. J Neurosci. 2015;35:10613-28.

15. Salawu FK, Danburam A, Olokoba AB. Non-motor symptoms of Parkinson's disease: diagnosis and management. Niger J Med. 2010;19:126-31.

16. Athauda $D$, Foltynie $T$. The ongoing pursuit of neuroprotective therapies in Parkinson disease. Nat Rev Neurol. 2015;11:25-40.

17. Aviles-Olmos I, Limousin P, Lees A, Foltynie T. Parkinson's disease, insulin resistance and novel agents of neuroprotection. Brain. 2013;136:374-84.

18. Du H, Yan SS. Mitochondrial medicine for neurodegenerative diseases. Int J Biochem Cell Biol. 2010;42:560-72.

19. Schapira $A H$, Patel $S$. Targeting mitochondria for neuroprotection in Parkinson disease. JAMA Neurol. 2014;71:537-8.

20. Beal MF, Oakes D, Shoulson I, Henchcliffe C, Galpern WR, Haas R, et al. A randomized clinical trial of high-dosage coenzyme Q10 in early Parkinson disease: no evidence of benefit. JAMA Neurol. 2014;71:543-52.

21. Kieburtz K, Tilley BC, Elm JJ, Babcock D, Hauser R, Ross GW, et al. Effect of creatine monohydrate on clinical progression in patients with Parkinson disease: a randomized clinical trial. J Am Med Assoc. 2015;313:584-93.
22. Batra P, Sharma AK, Khajuria R. Probing Lingzhi or Reishi medicinal mushroom Ganoderma lucidum (higher Basidiomycetes): a bitter mushroom with amazing health benefits. Int J Med Mushrooms. 2013;15:127-43.

23. Sanodiya BS, Thakur GS, Baghel RK, Prasad GB, Bisen PS. Ganoderma lucidum: a potent pharmacological macrofungus. Curr Pharm Biotechnol. 2009;10:717-42.

24. Wachtel-Galor S, Yuen J, Buswell JA, Benzie IFF. Ganoderma lucidum (Lingzhi or Reishi): a medicinal mushroom.In:Benzie IFF, Wachtel-Galor S, editors. Herbal Medicine: Biomolecular and Clinical Aspects. 2nd edition. Boca Raton (FL): CRC Press/Taylor \& Francis; 2011. Chapter 9.

25. Zhang R, Xu S, Cai Y, Zhou M, Zuo X, Chan P. Ganoderma lucidum protects dopaminergic neuron degeneration through inhibition of microglial activation. Evid Based Complement Altern Med. 2011;2011:156810.

26. Bhardwaj N, Katyal P, Sharma AK. Suppression of inflammatory and allergic responses by pharmacologically potent fungus Ganoderma lucidum. Recent Pat Inflamm Allergy Drug Discov. 2014;8:104-17.

27. Ma HT, Hsieh JF, Chen ST. Anti-diabetic effects of Ganoderma lucidum. Phytochemistry. 2015;114:109-13.

28. Chen LW, Wang YQ, Wei LC, Shi M, Chan YS. Chinese herbs and herbal extracts for neuroprotection of dopaminergic neurons and potential therapeutic treatment of Parkinson's disease. CNS Neurol Disord Drug Targets. 2007;6:273-81.

29. Lai CS, Yu MS, Yuen WH, So KF, Zee SY, Chang RC. Antagonizing beta-amyloid peptide neurotoxicity of the anti-aging fungus Ganoderma lucidum. Brain Res. 2008;1190:215-24.

30. Shen B, Truong J, Helliwell R, Govindaraghavan S, Sucher NJ. An in vitro study of neuroprotective properties of traditional Chinese herbal medicines thought to promote healthy ageing and longevity. BMC Complement Altern Med. 2013;13:373.

31. Zhao HB, Lin SQ, Liu JH, Lin ZB. Polysaccharide extract isolated from ganoderma lucidum protects rat cerebral cortical neurons from hypoxia/reoxygenation injury. J Pharmacol Sci. 2004;95:294-8.

32. Zhou Y, Qu ZQ, Zeng YS, Lin YK, Li Y, Chung P, et al. Neuroprotective effect of preadministration with Ganoderma lucidum spore on rat hippocampus. Exp Toxicol Pathol. 2012;64:673-80.

33. Zhou ZY, Tang YP, Xiang J, Wua P, Jin HM, Wang Z, et al. Neuroprotective effects of water-soluble Ganoderma lucidum polysaccharides on cerebral ischemic injury in rats. J Ethnopharmacol. 2010;131:154-64.

34. Guo SS, Cui XL, Rausch WD. Ganoderma lucidum polysaccharides protect against $\mathrm{MPP}(+)$ and rotenone-induced apoptosis in primary dopaminergic cell cultures through inhibiting oxidative stress. Am J Neurodegener Dis. 2016; 5:131-44.

35. Gokce EC, Kahveci R, Atanur OM, Gurer B, Aksoy N, Gokce A, et al. Neuroprotective effects of Ganoderma lucidum polysaccharides against traumatic spinal cord injury in rats. Injury. 2015;46:2146-55.

36. Zhang W, Zhang Q, Deng W, Li Y, Xing G, Shi X, et al. Neuroprotective effect of pretreatment with ganoderma lucidum in cerebral ischemia/reperfusion injury in rat hippocampus. Neural Regen Res. 2014;9:1446-52.

37. Ding H, Zhou M, Zhang RP, Xu SL. Ganoderma lucidum extract protects dopaminergic neurons through inhibiting the production of inflammatory mediators by activated microglia. Sheng Li Xue Bao. 2010;62:547-54.

38. Arduino DM, Esteves AR, Cardoso SM. Mitochondria drive autophagy pathology via microtubule disassembly: a new hypothesis for Parkinson disease. Autophagy. 2013;9:112-4.

39. Ghavami S, Shojaei S, Yeganeh B, Ande SR, Jangamreddy JR, Mehrpour M, et al. Autophagy and apoptosis dysfunction in neurodegenerative disorders. Prog Neurobiol. 2014;112:24-49.

40. Perier C, Bove J, Vila M. Mitochondria and programmed cell death in Parkinson's disease: apoptosis and beyond. Antioxid Redox Signal. 2012;16:883-95.

41. Millecamps S, Julien J-P. Axonal transport deficits and neurodegenerative diseases. Nat Rev Neurosci. 2013;14:161-76.

42. Saxton WM, Hollenbeck PJ. The axonal transport of mitochondria. J Cell Sci. 2012;125:2095-104.

43. Sheng $\mathrm{ZH}$. Mitochondrial trafficking and anchoring in neurons: new insight and implications. J Cell Biol. 2014;204:1087-98.

44. Kim-Han JS, Antenor-Dorsey JA, O'Malley KL. The parkinsonian mimetic, MPP+, specifically impairs mitochondrial transport in dopamine axons. J Neurosci. 2011:31:7212-21.

45. Mihaylova MM, Shaw RJ. The AMPK signalling pathway coordinates cell growth autophagy and metabolism. Nat Cell Biol. 2011;13:1016-23.

46. Scherz-Shouval R, Elazar Z. ROS, mitochondria and the regulation of autophagy. Trends Cell Biol. 2007;17:422-7.

47. Alers S, Loffler AS, Wesselborg S, Stork B. Role of AMPK-mTOR-Ulk1/2 in the regulation of autophagy: cross talk, shortcuts, and feedbacks. Mol Cell Biol. 2012;32:2-11.

48. Inoki K, Kim J, Guan KL. AMPK and mTOR in cellular energy homeostasis and drug targets. Annu Rev Pharmacol Toxicol. 2012:52:381-400. 
49. Kazlauskaite A, Muqit MM. PINK1 and Parkin-mitochondrial interplay between phosphorylation and ubiquitylation in Parkinson's disease. FEBS J. 2015;282: 215-23.

50. Scarffe LA, Stevens DA, Dawson VL, Dawson TM. Parkin and PINK1: much more than mitophagy. Trends Neurosci. 2014;37:315-24.

51. Narendra DP, Youle RJ. Targeting mitochondrial dysfunction: role for PINK1 and Parkin in mitochondrial quality control. Antioxid Redox Signal. 2011;14: 1929-38.

52. Barodia SK, Creed RB, Goldberg MS. Parkin and PINK1 functions in oxidative stress and neurodegeneration. Brain Res Bull. 2016;133:51-9.

53. Boh B, Berovic M, Zhang J, Zhibin L. Ganoderma lucidum and its pharmaceutically active compounds. Biotechnol Annu Rev. 2007;13:265-301.

54. Sliva D. Cellular and physiological effects of Ganoderma lucidum (Reishi). Mini Rev Med Chem. 2004;4:873-9.

55. Boh B. Ganoderma lucidum: a potential for biotechnological production of anticancer and immunomodulatory drugs. Recent Pat Anticancer Drug Discov. 2013;8:255-87.
56. Ferreira IC, Heleno SA, Reis FS, Stojkovic D, Queiroz MJ, Vasconcelos MH, et al. Chemical features of Ganoderma polysaccharides with antioxidant, antitumor and antimicrobial activities. Phytochemistry. 2015;114:38-55.

57. Xu Z, Chen X, Zhong Z, Chen L, Wang Y. Ganoderma lucidum polysaccharides: immunomodulation and potential anti-tumor activities. Am J Chin Med. 2011;39: $15-27$.

58. Li X, Gong H, Yang S, Yang L, Fan Y, Zhou Y. Pectic bee pollen polysaccharide from Rosa rugosa alleviates diet-induced hepatic steatosis and insulin resistance via induction of AMPK/mTOR-mediated autophagy. Molecules. 2017;22:E699.

59. Liao LZ, Chen YL, Lu LH, Zhao YH, Guo HL, Wu WK. Polysaccharide from Fuzi likely protects against starvation-induced cytotoxicity in $\mathrm{H} 9 \mathrm{c} 2$ cells by increasing autophagy through activation of the AMPK/mTOR pathway. Am J Chin Med. 2013;41:353-67.

60. Lu L, Huang YF, Chen DX, Wang M, Zou YC, Wan H, et al. Astragalus polysaccharides decrease muscle wasting through Akt/mTOR, ubiquitin proteasome and autophagy signalling in 5/6 nephrectomised rats. J Ethnopharmacol. 2016;186:125-35. 